\title{
MACHIAVELLIANISM AND PERSONAL TRAITS IN YOUNG AGE
}

\author{
Irina Kurapova \\ Larisa Lezhnina \\ Mari State University, Russian Federation
}

\begin{abstract}
The article is devoted to one of the vital problems of modern society, the problem of Machiavellianism. It is noted that manipulative forms of interaction between people become common, and it can lead to a tendency to use the manipulation by an increasing number of people and, in its turn, to the loss of openness, sincerity, and congruence of communication. The results of an empirical study of Machiavellianism and its interrelationship with personality traits in young age are discussed. The study is based on a dispositional approach to the person, suggesting that it consists of reliable, stable, interrelated elements (properties, traits) that determine its internal essence and behavior. Differences in the behavior of people are explained by the differences in the intensity of personality traits. The article shows that adolescence is one of the most sensitive ways to consolidate manipulative strategies in the behavior of a person. The obtained results prove the existence of a interrelationship between Machiavellianism and a number of personality traits, according to the theory of $R$. B. Cattell. Among such personality traits are communicative (closed), regulative (low normative, low self-control behavior), emotional (rigidity) and intellectual (radicalism). Knowledge of the personal profile of a personality prone to Machiavellianism in adolescence will allow continuing the study within the framework of studying ways of preventing extreme manifestations of manipulative behavior and widening the range of constructive patterns of youth behavior.
\end{abstract}

Keywords: Machiavellianism, manipulation, interpersonal relations, personal traits, young age.

\section{Introduction}

The changing social and economic conditions in Russia give rise to new demands on the subject of modern society, which in turn forms new styles of relations between people. Not always these changes indicate an increase in harmony, mutual understanding between people. More often they began to show the spread of asymmetrical interpersonal relations - rivalry, competition and manipulation (Grachev \& Melnik, 2002). The problem of manipulating the personality, its consciousness and behavior was repeatedly posed in the 20th century by domestic and foreign researchers (Christie \& Geis, 1970; Jones \& Paulhus, 2009; Znakov, 2007; Shostrom, 1967). 
On the one hand, there are several areas of professional activity, where the possession of manipulation techniques plays a decisive role in achieving success (management, culture, jurisprudence, journalism, advertising, applied sociology, religion, politics, etc.). Also in the social sphere, the situations of approval of such forms of behavior as manipulation, aggression, fierce competition are increasingly noted. On the one hand, a person can become the victim of manipulative techniques against himself, and the person using manipulation exposes himself to serious deformities. Interpersonal interaction, based on manipulative methods, is characterized by an attitude toward another person as a means of achieving his own goals and reducing the qualities of the subject of decision-making in the interlocutor.

In this regard, some scientists believe that in the 21st century, destructive manipulation of people, public opinion and mass consciousness can, along with national conflicts, environmental disasters and demographic disasters, turn into a global world problem of the beginning of the third millennium (Egorova, 2002; Shibaeva \& Tarasova, 2014; Ryumshina, 2003).

The purpose of the research was to study the intensity of Machiavellianism in adolescence and its relationship with personality traits.

The object of the research is Machiavellianism, the subject is the interrelationship between Machiavellianism and personality traits in the young age.

\section{Overview}

In relationships built on manipulation, the positions between participants of interpersonal interaction are often distributed on the basis of the principle of "a winner-a defeated", "a winner-a loser”. At the same time, the steady desire to manipulate other people brings immediate benefits to the manipulator himself, but can turn into personal and social problems for him in a long time perspective (Znakov, 2007; Ryumshina, 2003).

Machiavellianism should be regarded as a stable personality trait, expressing the system of human relations to other people, social reality (Paal \& Bereczkei, 2007). There are such psychological components of Machiavellianism as persuasion of the subject that they can and should be manipulated when communicating with other people; possession of skills of manipulation. Machiavellianism as a property of the personality reflects the desire and intention of a person to manipulate others in interpersonal relationships (Znakov, 2007).

The tendency to manipulate other people in interpersonal relationships is called Machiavellianism by western psychologists R. Christie and F. Geis (Christie \& Geis, 1970). They connect the predisposition of manipulative style 
of communication with personal traits of a person. Machiavellianism reflects the denial of a person's belief that most people need to be trusted, that they are independent and may have a strong will. The high level of manipulation means resistance to social influence, calm and lack of emotionality, orientation to the goal, the desire to achieve the goal in a competitive struggle with others, a cold rational initiative. The traits of such a person are determined by psychological processes: by fixing on the precise cognitive characteristics of the situation and concentrating attention and actions on freedom. Usually such people are leaders (Jones \& Paulhus, 2009).

As a rule, people with a low level of manipulation, on the contrary, are characterized by excessive trustfulness, sensibility to social influence, orientation to the personality, acceptance of the social structure and adherence to it. They are characterized by frequent interference of emotions in a rational assessment of the situation, dependence on emotions and pressure from the side (Znakov, 2007).

The researchers also identified the following common psychological characteristics of the Machiavellian personality: developed intelligence, courage, ambition, domination, perseverance, selfishness. In general, there are individual manipulative traits in every person (Shostrom, 1967). Another characteristic trait of the manipulator is a tendency to superficial erudition, the aim of which is to make an impression, catch others, and then control them (Egorova, 2009; Larina, 2010; Shostrom, 1967). The manipulator likes to control and is dependent on this need.

According to E. Shostrom, the lifestyle of the manipulator is characterized by lies, unconsciousness, control and cynicism. Being unable to appreciate him as he is, the manipulator feels misunderstood, unrecognized and underappreciated. The more he depreciates himself, the more part of himself he has to deny (Shostrom, 1967).

Modern research suggests that the maximum degree of inclination to manipulate falls on youth (Znakov, 2007; Ryumshina, 2003), while there is no detailed study of this phenomenon. It is at this age that young people are in a situation of personal and professional choice and self-determination, which are based on values that set the orientation for the future. Intermediate social status and the status of youth determine the characteristics of his psyche.

Young people have a special sensitivity, as a result, young people are the most unprotected, vulnerable, lonely and psychologically helpless before difficulties in the life. Often they are not ready for the new tough demands of society, they are not always able to make an independent choice and take responsibility for their behavior, for their future, and therefore find themselves in stressful situations. 
Youth in the modern period of socio-economic development of the society and the state was in the conditions of continuing instability of public consciousness, when there are no claimed ideals from the past, but in the present there are still no new benchmarks suitable for the ongoing development in the country and in the world for the forthcoming development, personal, national self-determination. Therefore, today, it is very difficult for young people to single out and assimilate norms of adult life. Hence - confusion and uncertainty in the future (Feldshtein, 2004).

Along with this, the present stage of the social development of society has "shifted" the border of all ages towards an earlier maturity in the psychological and "activity" meaning. This process occurs according to many "formal" characteristics, but at the same time the social infantilism among the youth and youth is paradoxically intensified. In this regard, the importance of the young age is growing both for the successful formation of the personality and for the productive social development of society (Feldshtein, 2004). With the complication of life activity in the young age, there is not only a quantitative expansion of the range of social roles and interests, but also a qualitative change in them. In the young age, there are more and more "adult" social roles with the consequent greater measure of independence and responsibility.

In adolescence life, the formation of moral consciousness is intense, value orientations and ideals, a sustainable worldview, and civic qualities of the individual are developed and formed. The worldview search in the young age includes the social orientation of a person, the realization of oneself as a particle of the social community (Feldshtein, 2004).

Therefore, a more detailed study of Machiavellianism in the young age and its interrelation with personality traits is necessary.

\section{Research methodology}

Research hypothesis: in the young age Machiavellianism as a personality trait is associated with other personal traits and forms a certain profile prone to manipulating personality.

The theoretical and methodological basis of the research consists of the fundamental principles of the theory of manipulation in interpersonal communication (Shostrom, 1967; Christie \& Geis, 1970); the concept of Machiavellian personality (Znakov, 2007), dispositional personality theories (Cattell, 1990).

Among the methods of research both theoretical analysis of sources and empirical methods - testing were used. A technique of the research the Machiavellian personality of V. V. Znakov was used to study Machiavellianism; 
for the study of personality traits - a 16-factor personality questionnaire by Cattell. To confirm the reliability of the results obtained, methods of mathematical statistics (correlation analysis, the Mann-Whitney U test) were applied.

An empirical study was conducted in which the participants were senior pupils of the secondary schools of the Republic of Mari El and the 1st and 2nd year students of Mari State University, 97 young people in total.

\section{Results}

The results of the research of Machiavellianism showed that one third of respondents have a high level of expression of this personality trait. At the same time, the average level of Machiavellianism prevails (56.5\%). Among the subjects with a low propensity for manipulation, there are more students, and it proves the opinion of scientists that with age the severity of Machiavellianism is somewhat reduced.

To test the hypothesis about the Machiavellian personal profile, the personality traits of respondents with high, medium and low Machiavellian levels were determined, significant differences were revealed.

The personality traits of the subjects, obtained according to the "Method of Multifactor Research of the Personality of R. Cattell", were analyzed according to the level of Machiavellianism of the respondents. Thus, students with a high level of Machiavellianism have high rates of radicalism (Q1) and average selfmonitoring indicators (Q3), rigidity (I), and normative behavior (G).

It should be noted that all measured personality traits are divided into several groups: communicative, intellectual, emotional and regulative. In the research, statistically significant differences were found in students with a high and low level of Machiavellianism only in the expression of intellectual factors (factor $\mathrm{Q} 1 \mathrm{U}_{\mathrm{emp}}=62,5, \mathrm{p}=0.000$ ), emotional (factor $\mathrm{I} \mathrm{U}_{\text {emp }}=83.5, \mathrm{p}=0.004$ ) and regulatory traits (factor $\mathrm{G} \mathrm{U}_{\mathrm{emp}}=92.5, \mathrm{p}=0.01$, factor $\mathrm{Q} 3 \mathrm{U}_{\mathrm{emp}}=66.5, \mathrm{p}=$ 0.001). Communicative traits of a person with different levels of Machiavellianism do not differ.

Characteristics of the identified personality traits of respondents with Machiavellianism are presented in Table 1.

It can be concluded that in the young age a Machiavellian is characterized by such intellectual traits as the presence of intellectual interests, analytical thinking, distrust to authorities, susceptibility to changes; such emotional properties - lack of sentimentality, self-confidence, severity, rationality; regulatory features - low discipline, irresponsibility, impulsiveness, lack of agreement with generally accepted moral rules and standards. 
Table 1 Description of personal traits of respondents with a high level of Machiavellianism according to the questionnaire of R. B. Cattell

\begin{tabular}{|l|l|}
\hline Factor & \multicolumn{1}{|c|}{ Description } \\
\hline I- & $\begin{array}{l}\text { The lack of sentimentality, self-confidence, severity, rationality, flexibility } \\
\text { in judgments, pragmatism, sometimes some cruelty and callousness towards } \\
\text { others, rationality, logic. }\end{array}$ \\
\hline G- & $\begin{array}{l}\text { Inclination to instability, susceptibility to the influence of feelings, chance } \\
\text { and circumstances. He indulges his desires, does not make efforts to fulfill } \\
\text { group requirements and norms. Lack of organization, irresponsibility, } \\
\text { impulsiveness, lack of agreement with generally accepted moral rules and } \\
\text { standards, flexibility in relation to social norms, freedom from their } \\
\text { influence, sometimes unprincipled and inclined to antisocial behavior. }\end{array}$ \\
\hline Q3- & $\begin{array}{l}\text { Low discipline, self-indulgence, dependence on moods, inability to control } \\
\text { one's emotions and behavior. }\end{array}$ \\
\hline Q1+ & $\begin{array}{l}\text { Freethinking, experimentation, the presence of intellectual interests, } \\
\text { developed analytical thinking, receptivity to changes, new ideas, distrust to } \\
\text { authorities, refusal to accept anything on faith, focus on analytical, } \\
\text { theoretical activity. }\end{array}$ \\
\hline
\end{tabular}

Respondents with a low level of Machiavellianism, on the contrary, are characterized by conservatism, sensitivity, ability to self-control and normative behavior.

To reveal the interrelationship between the level of Machiavellianism and personal traits, a correlation analysis (rank correlation of Spearman) was carried out. The interrelation of Machiavellianism with such personality traits as "isolation - sociability" ( $r=-0.23, p=0.05)$ was revealed; "low normative behavior - high normative behavior" $(r=-0.22, p=0.05)$; "rigidity - sensitivity" $(r=-0.23, p=0.05)$; "low self-control - high self-control" $(r=-0.33, p=0.01)$; “conservatism - radicalism” ( $\mathrm{r}=0.36, \mathrm{p}=0.01)$.

So, the strongest interrelation is revealed between manipulation and radicalism. Hence it follows that the Machiavellians are characterized by experimentation, analytical thinking, free-thinking, distrust to authorities. Also, a strong reverse statistical interrelationship is revealed between Machiavellianism and high self-control: the more Machiavellianism is revealed, the lower is the level of self-control. The average negative interrelationship exists between Machiavellianism and sociability, normative behavior, sensitivity.

\section{Summary}

The research showed that the tendency to manipulate other people in interpersonal communication and in mass information impact is one of the characteristic features of a modern man. In this case, this problem becomes the most urgent for young age. It carries a 
certain internal crisis, sensitivity, as a result of which young people are most vulnerable and psychologically helpless before difficulties of the life. Therefore, young men constitute a risk group for the development and consolidation of Machiavellianism as personality traits (Znakov, 2007; Ryumshina, 2003).

The study of psychological and pedagogical literature on the problem of manipulation and Machiavellianism showed that the personality of a manipulator has not been studied enough, it is possible to trace completely contradictory characteristics in its description, and in this connection an attempt was made to describe the personal profile of a Machiavellian in the young age.

Machiavellianism, according to V. V. Znakov, is a stable personality trait and manifests itself in the system of human relationships with other people. Machiavellianism reflects the desire and intention of a person to manipulate others in interpersonal relationships.

The results of the empirical research showed that in the young age the category of students with high level of Machiavellianism indices is singled out.

Machiavellianism as a personality quality is included in the personal profile of the respondents and is associated with communicative (asocial), regulative (low normative, low self-control behavior), emotional (rigidity), intellectual (radicalism) personality traits.

The results of the research can become the basis for further theoretical and methodological development of the problem of Machiavellianism of personality at different age stages. In this paper, the relationship between Machiavellianism and personality characteristics in the young age is shown; general characteristics of young people with a high level of Machiavellianism are given.

\section{References}

Cattell, R. B. (1990). Advances in Cattellian personality theory. In L. A. Pervin (Ed.). Handbook of personality: Theory and research (pp. 101-110). New York: Guildford.

Christie, R., \& Geis, F. (1970). Studies in Machiavellianism. New York: Academic Press.

Egorova, M. S. (2009). Machiavellianism in the Structure of Personal Properties. Vestnik Perm. state. ped. University. Series 10, Differential Psychology, 1/2, 65-80. Retrieved from http://psystudy.ru/index.php/num/sputniks/44-articles/427-egorova-ms-2009machiavellianism.html (In Russian)

Feldstein, D. I. (2004). The psychology of growing up: the structural and content characteristics of the process of personality development: Selected Works $2^{\text {nd }}$ ed. Moscow: MPSI, Flinta. (In Russian)

Grachev, G. V., \& Melnik, I. K. (2002). Manipulation of personality: the organization, methods and technologies of information-psychological impact. Moscow: Eksmo. (In Russian)

Jones, D. N., \& Paulhus, D. L. (2009). Machiavellianism. In M.R. Leary \& R.H. Hoyle (Eds.), Handbook of individual differences in social behavior (pp. 93-108). New York: Guilford Press.

Larina, A. D. (2010). Approaches, attitudes and prospects in the study of Machiavellianism. Questions of psychology, 3, 75-83. (In Russian)

Paal, T., \& Bereczkei, T. (2007). Adult theory of mind, cooperation, Machiavellianism: The effect of mindreading on social relations. Personality and Individual Differences, 43, 541-551.

Ryumshina, L. I. (2003). Psychology of human manipulation (value-semantic aspect) (pp.1948). Rostov-on-Don: Publishing House of the RSU. (In Russian) 
Shibaeva, G. E., \& Tarasova, Yu. I. (2014). Machiavellianism as a strategy of social behavior of a person. Culture and education, 2, 213-218. Retrieved from http://gi.vlsu.ru/ fileadmin/departments/Educational_Psychology/Konferencii_i_seminary/Sbornik_Molo dezh_i_budushchee_2014.pdf(In Russian)

Shostrom, E. L. (1967) Man, the manipulator: The Inner Journey from Manipulation to Actualization. Nashville, Tenn.: Abingdon Press.

Znakov, V. V. (2007). Machiavellianism, manipulative behavior and mutual understanding in interpersonal communication. In Understanding in thinking, communication, human being (pp.171-184). Moscow: Publishing house "Institute of Psychology of the Russian Academy of Sciences”. (In Russian) 